\title{
Leveraging Lean Six Sigma to Culture, Nurture, and Sustain Assessment and Change in the Academic Library Environment
}

\section{Sarah Anne Murphy}

This paper explores the application of Lean Six Sigma, a business improvement philosophy and methodology, in the academic library environment as one means to nurture and sustain a culture of assessment and change. It includes an overview of the philosophy and an example of an actual virtual reference improvement project that was conducted using Lean Six Sigma tools and principles at The Ohio State University Libraries. It concludes with a discussion of the benefits and limitations of deploying a Lean Six Sigma initiative within a library organization.

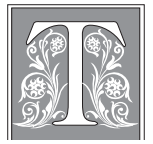

he library community has recently developed a renewed interest in assessment, with numerous conferences exploring the issue arranged by professional organizations and groups. ${ }^{1}$ While some highlight the technical aspects of collecting statistics and other forms of output data, others explore the linkage of data to outcomes. A few have touched on the need to foster a culture of assessment within a library organization, leading to questions of how such a culture is created, nurtured, and sustained. Fortunately, the library community can borrow a number of philosophies and methodologies from business that have proved successful in creating organizations that are responsive to change. This paper will focus on Lean Six Sigma, a business improvement methodology that offers an organization a framework and tools to identify, approach, and prioritize quality improvement initiatives to reduce variation and waste. It will begin with an overview of the Lean Six Sigma philosophy and its application in a service environment. It will then explore the application of Lean Six Sigma in an academic research library, using an actual virtual reference improvement project at The Ohio State University Libraries as an example. It will conclude with a discussion of the benefits and limitations of using Lean Six Sigma within a library environment to create and sustain a culture of assessment and change.

\section{Lean Six Sigma in the Service Environment}

Lean Six Sigma represents the amalgamation of Lean Manufacturing and the Six Sigma process improvement philoso-

Sarah Anne Murphy is Coordinator of Research and Reference at The Ohio State University Libraries; e-mail: Murphy.465@osu.edu. 
phies. ${ }^{2}$ While Lean Manufacturing focuses on eliminating waste in production processes and improving flow, Six Sigma focuses on eliminating variation by identifying its root causes. Both systems are structured as change initiatives and offer tools, strategies, and, most important, a discipline for identifying and eliminating inefficiencies, defects, and errors within an organization's processes to accelerate improvements in customer satisfaction, cost, quality, process speed, and invested capital. Both systems are project based, and complement each other, emphasizing the collection of data to inform and drive change. While Six Sigma focuses on bringing a process into statistical control, Lean functions to improve process speed and reduce invested capital.

Originally conceived for the manufacturing environment, Lean Six Sigma translates well to service industries such as libraries. Service products have unique attributes that distinguish them from durable goods. ${ }^{3}$ Most markedly, services are both intangible and heterogeneous, inviting variability in processes as customers and providers contribute to the inputs and outputs of the service product. Services are perishable, challenging organizations to schedule employees to accommodate fluctuations in customer demand. The customer also functions as a co-producer throughout the service process, consuming the product as it is created.

Traditionally, Lean Six Sigma project success is defined in terms of revenues minus costs. The value a customer perceives in a service or product influences revenue positively, generating increased profits. Libraries can focus on maximizing customer value and minimizing cost when conducting a Lean Six Sigma initiative. All nonprofit organizations, including libraries, must maximize customer value to remain relevant by focusing on the customer's perceived benefits minus their perceived costs or liabilities for using the organization's products or services. ${ }^{4}$ Benefits and liabilities reflect not only the tangible and economic consequences of consuming a product or service, but include the psychological and convenience aspects of using that service.

Why should a library organization concern itself with adapting Lean Six Sigma for eliminating variation, defects, errors, and inefficiencies in their processes? The costs of quality are often unseen within an organization. ${ }^{5}$ Poor quality that results from products or services not meeting customer needs, for example, leads to complaints, rework, delays, sales loss, and other consequences that require both human and financial resources to address. Good quality requires product testing, quality improvement teams and initiatives, process error-proofing, and other activities to ensure that the customer does not receive a poor quality product or service. Good quality also requires the dedication of significant human and financial resources. When variation within a process or waste increases, the costs of both good and poor quality increase, as both require the identification of deficiencies caused by errors in products or inefficiencies in processes to address. The Lean Six Sigma discipline provides a formal learning process and infrastructure for studying these issues. As noted by Gee, with an analogy to teaching a child to ride a bike:

"Businesses wobble, too, in their processes and, in Six Sigma terminology, this wobbling is the variation that needs continual feedback to help correct and stabilize. Unlike riding a bike, wherein once learned, it becomes natural and smooth going, businesses continue to wobble in their processes and may fall and not be able to get back up. The institution of Six Sigma methodology is a closed feedback loop to prevent instability in processes." 6

Lean Six Sigma initiatives are usually organizationwide and structured hierarchically with a Project Champion at the top, followed by Master Black Belts, Black Belts, Green Belts, and Project 
Team Members. Individuals at each level within the hierarchy are educated and trained in Lean Six Sigma techniques and philosophy to implement improvement programs effectively. The Project Champion is responsible for driving the vision of the organization's Lean Six Sigma initiative, by prioritizing and selecting projects for completion, and empowering and providing resources for the project teams to conduct their work. Master Black Belts are Lean Six Sigma experts, having been trained in the Lean Six Sigma Black Belt Body of Knowledge and successfully completed a number of Lean Six Sigma Projects. Master Black Belts are responsible for coaching, training, and mentoring Black Belts within the organization and serve as the resident expert on the Lean Six Sigma methodology and associated quality tools. Black Belts have also received training in the Lean Six Sigma Black Belt Body of Knowledge and receive coaching and support from the Master Black Belts. Black Belts are responsible for leading and implementing an organization's Lean Six Sigma projects and training the Green Belts within an organization to assist them. Green Belts have received training in the Lean Six Sigma Green Belt Body of Knowledge and serve on teams led by Black Belts. A Project Team member represents any other individual who serves on a project team.

Lean Six Sigma projects focus on variables that customers define as "critical to quality" and follow either Lean's 5S methodology or the Six Sigma's systematic DMAIC framework. Since the case study reported in this paper involved a process variation problem, the author will focus on describing the DMAIC process. ${ }^{7}$ The DMAIC acronym stands for Define, Measure, Analyze, Improve, and Control. During the Define phase, the project team drafts a project charter, outlining the scope, stakeholders, desired outcomes, and timeline of the project. The process examined is mapped to determine the input variables $(x)$, which contribute to the process output or outcome $(\mathrm{Y})$. This is then represented by the mathematical function $\mathrm{Y}=f(\mathrm{x})$. Thus, if a library was interested in examining the time it took a patron to request and receive a book from another library, the turnaround time would be represented by "Y." All of the variables influencing the turnaround time for this process, such as the time for the patron to complete and submit an Interlibrary Loan form, the time for the library staff to process and submit the form, the time for the lending library to retrieve and process the ILL request, the time for mailing the request, the time for the borrowing library to process the received book, and, finally, the time for the patron to check the requested book out, would represented by "x."

During the Measure phase, the project team develops a data collection plan to measure the performance of a process and establishes a baseline capability level for the process. The project team then analyzes the data collected during the Analyze phase, with the goal to identify and confirm the root cause(s) of the problems identified or opportunities for improvement. Potential solutions are then brainstormed, tried, and evaluated during the Improve phase. Once the best solution is identified, a plan for implementing this solution is created and executed. Finally, the team creates methods for monitoring and sustaining the improvement during the Control phase of the project.

While a few libraries and library researchers have begun to explore the application of the Six Sigma philosophy and methodologies for library services, there are currently no reports of libraries adopting Lean Six Sigma for improving their organizational efficiency and effectiveness. ${ }^{8}$ Outside of libraries, Lean Six Sigma has been shown to improve the efficiency and effectiveness of service products with processes similar to those found in library organizations. ${ }^{9}$

\section{Application of Lean Six Sigma in an Academic Research Library}

The author of this paper received training in the Lean Six Sigma Black Belt Body 
of Knowledge in the fall of 2006 and participated on project teams outside the library organization to gain experience. An opportunity arose in the spring of 2008 to conduct a study of the OSU Libraries' e-mail reference service with the assistance of MBA students enrolled in an OSU Fisher College of Business course on Service Quality Management. The MBA students served with the author on the project team. It is important to note that The Ohio State University Libraries currently has not deployed a formal Lean Six Sigma initiative, with a formalized hierarchy of Project Champions, Master Black Belts, Black Belts, Green Belts, and Project Team Members. Still, this project was conducted as a formal Lean Six Sigma Project, and the experience elicited useful information for improving and controlling the Libraries' current processes for managing and answering patron questions received via e-mail through its AskA-Question Web site (figure 1). Since an initial review of selected data indicated a process variation problem, the project team chose the DMAIC framework to structure their approach to studying the problem.

\section{Define}

The OSU Libraries uses OCLC's QuestionPoint reference management service to distribute and manage e-mail questions received through its Ask-A-Question Web site to a dedicated staff of 45 public service librarians and paraprofessional library assistants spread over 22 campus locations. Questions received through the Ask-A-Question Web site are of interest to the OSU Libraries, as roughly 15 percent of all questions answered in 2007 were received via e-mail, and the site functions as the only mechanism for select library patrons to interface with library employees. The university also considers the Libraries' Web site to serve as an outreach function that nurtures the learning needs of students, faculty, alumni, and any other individual seeking information.

A preliminary review of answers to e-mail questions submitted to the Ask-AQuestion Web site in 2007 indicated problems with the quality and consistency of communications between library employees and patrons. In some instances, library patrons were required to wait up to 12 days for an answer to their questions. In others, the answers provided did not ad-

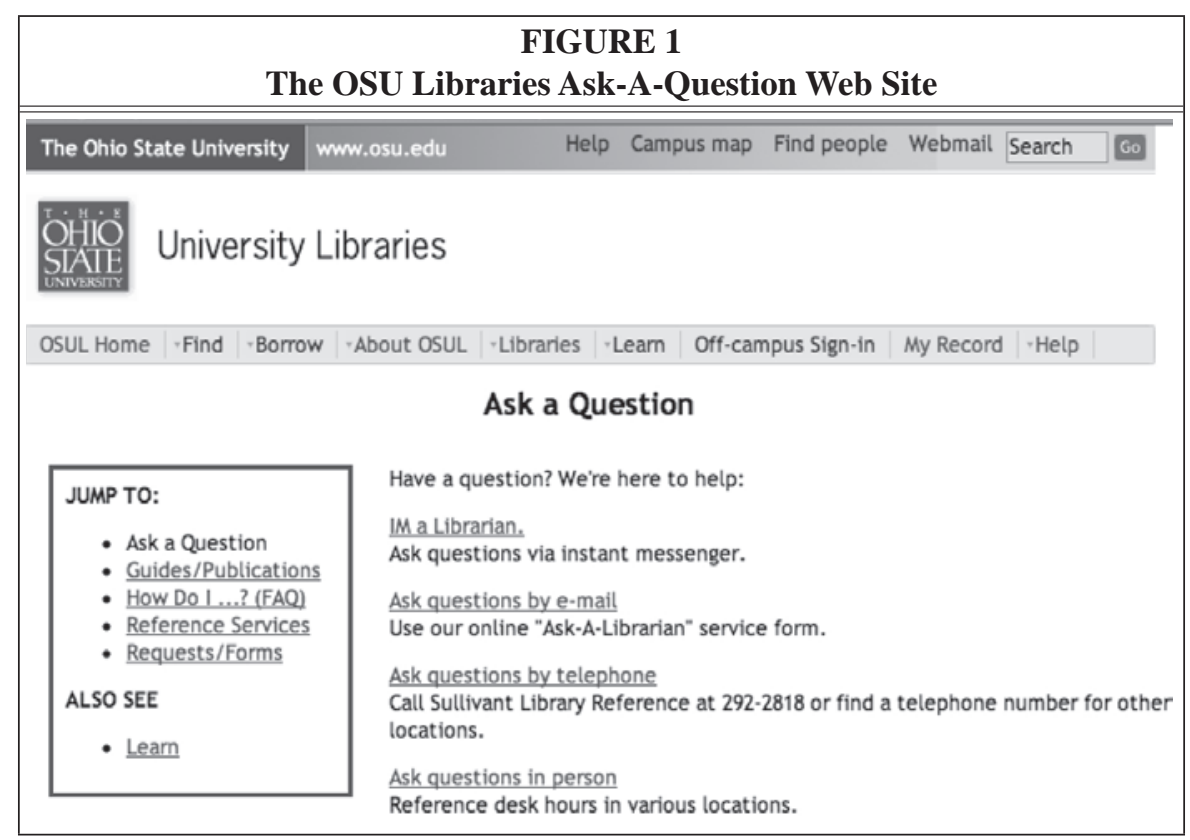


dress the question the patron asked. Thus, during the Define phase, the project team drafted a project charter, indicating the scope, mission, and intended outcomes of the project. For this project, the mission was to improve question turnaround time along with the quality and consistency of communications between library employees and patrons.

A number of tools can be employed during the Define phase to help a project team reach agreement on the process to

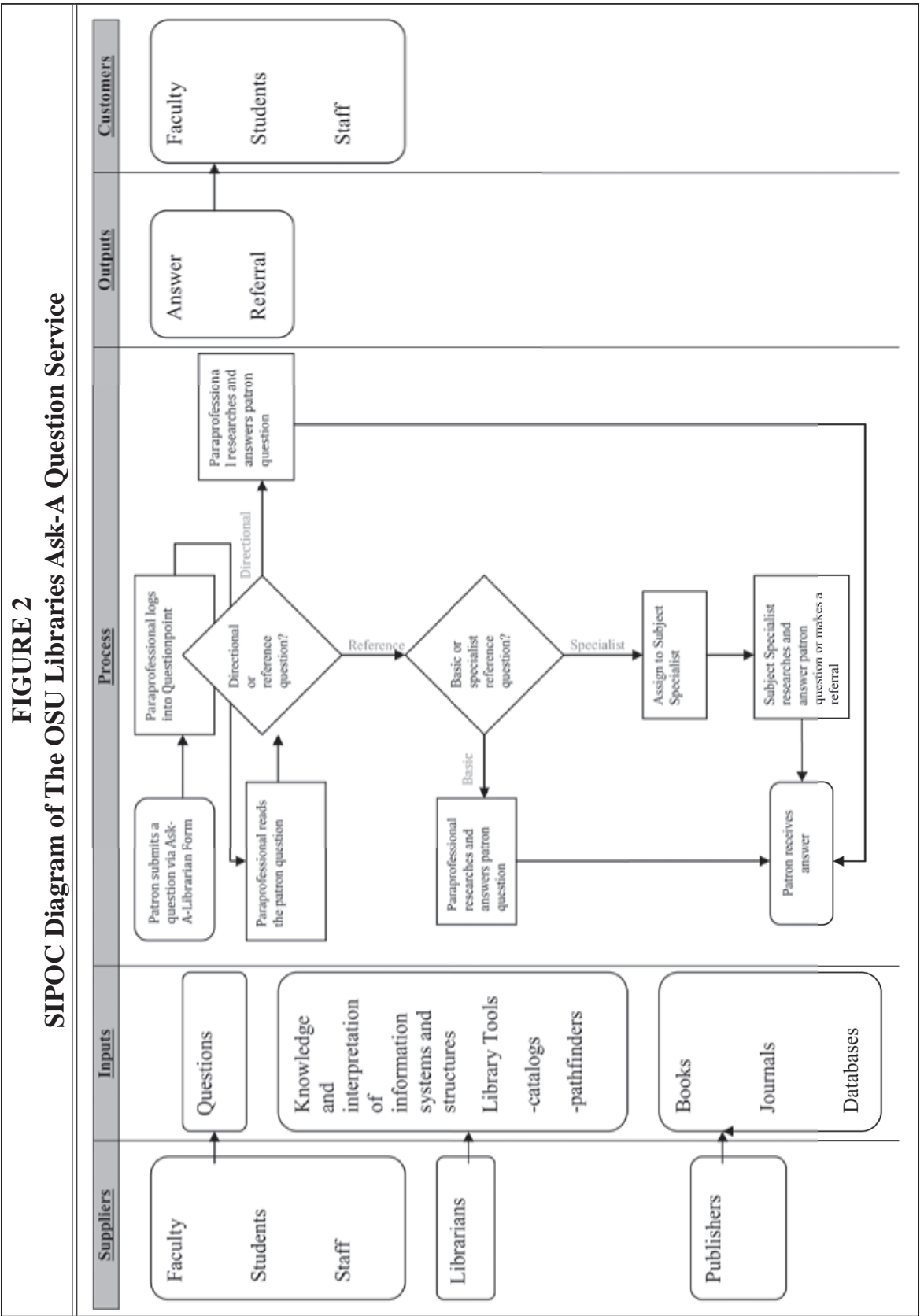


be improved, who their customers are along with their customer's expectations for products and services, and the scope of the process involved. For this project, the team chose to construct a Suppliers, Inputs, Process, Outputs, and Customers (SIPOC) process diagram (figure 2). The SIPOC diagram of the OSU Libraries' e-mail reference service illustrates that patron questions submitted via the e-mail question form on the Libraries' Ask-A-Question Web site are immediately transferred into the Questionpoint system. A paraprofessional staff member reads these questions during regular working hours, 8:00 a.m.-5:00 p.m. Monday through Friday. The paraprofessional then decides whether the question is a directional or reference question, using the definitions provided by the Association of Research Libraries for its annual survey of member libraries. ${ }^{10}$ If the paraprofessional determines a question is directional, he or she should answer the question immediately. For reference questions, if an answer can appropriately be provided with a basic search by title, author, or keyword in the library catalog or a general library database, the question is considered to be a basic reference question and can be answered immediately by the paraprofessional. Questions that require specific knowledge of a subject area, interpretation, or a broad range of resources to answer are considered specialized and are assigned by the paraprofessional to an appropriate librarian subject specialist. Note that students, faculty, and staff both provide input to the process through the questions they submit and receive the output of the process in the answers or referrals provided for their questions.

\section{Measure}

While the nature of library reference work requires a high degree of interaction to understand and provide a customized response to a patron's information need, the RUSA Guidelines for the Behavioral Performance of Reference and Information Services Providers (RUSA Guidelines) can serve as operational definitions when measuring quality in a face-to-face or virtual reference transaction. ${ }^{11}$ The RUSA Guidelines specify what behaviors are expected of a reference librarian or paraprofessional staff member during the reference transaction, recognizing that "in all forms of reference services, the success of the transaction is measured not only by the information conveyed, but the positive or negative impact of the patron/ staff interaction."

For the purpose of this study, librarian and paraprofessional answers to patron questions were evaluated for conformance with the RUSA Approachability, Listening/Inquiring, and Follow-up guidelines, which compel librarians to use welcoming language and ask questions to understand the content and scope of a patron's information need during the reference transaction so that an effective search strategy can be constructed and refined. For e-mail questions, this means a librarian may need to send the patron a follow-up e-mail to ask for additional information or paraphrase the question asked to be sure it was understood. In some instances, however, if the librarian can interpret the patron's question in one or two ways, it may be more timely and effective to send an e-mail reply with answers for both interpretations. Follow-up behaviors include asking patrons whether they were satisfied with the answer, encouraging them to ask again if the information provided wasn't exactly what he or she was looking for, or referring patrons to another library or institution when a query cannot be satisfactorily answered using the library's resources.

To determine a baseline capability level for the process, all 586 e-mail questions received and answered by library employees using the Questionpoint service from January 1, 2008, to March 17, 2008, were printed and prepared for analysis. Answers that did not conform to the RUSA Guidelines for Approachability, Listening/Inquiring, and Follow-up Behaviors were marked as defective in an 
Excel spreadsheet. Incorrect or incomplete answers were also marked as defective, in addition to instances where a patron was inappropriately denied service or when the patron's question was referred to the wrong department or librarian to answer. Additional data were recorded to determine the turnaround time to provide answers to patron queries, the librarian or group of librarians assigned to answer the question, and whether the question was a directional, basic, or specialist reference question. These data were determined to be critical to identifying breakdowns in the OSU Libraries' e-mail reference service process to identify and address the patterns and root causes of these problems.

Overall, 548 defects were identified in the answers to the 586 questions, with six opportunities for a defective answer per question. In Six Sigma, the baseline capability level for a process is calculated by determining the Defects Per Million Opportunities (DPMO) for the process, and then locating Sigma Level in a Sigma Conversion table. ${ }^{12}$ To calculate DPMO, the total number of defects is first multiplied by $1,000,000$ and then divided by the number of defect opportunities per unit multiplied by the total number of units. For this project, DPMO was calculated to be 155,858 or $\left(\left(548^{*} 1000000\right) /\left(586^{*} 6\right)\right)$, resulting in a Sigma Level of 2.5. This calculation serves as a benchmark and is later required, in the Analyze and Improve phases, to determine whether improvements to the process are successful.

\section{Analyze}

Pareto charts were constructed to help the OSU Libraries prioritize which defect areas to address first (figure 3). Pareto charts graphically represent the theory that 20 percent of defects are responsible for the 80 percent of problems. ${ }^{13}$ By ranking the occurrence of defects by category in descending order, an organization can better understand the occurrence of a problem and prioritize which problems to address.

The Pareto chart revealed that failure to conform to RUSA Guidelines for Followup Behaviors was the most frequently occurring defect, with 263 answers lacking follow-up language and questions. Representing 48 percent of all defects, solutions to minimize and address this issue were explored during the Improve phase. The Pareto chart also indicated that 47 patrons were inappropriately denied service. Since this is a defect that should never occur, further investigation into the root cause of this defect was required. In some instances, librarians may have answered the patron's question by phone and failed to annotate this in the question record.

For turnaround time, the OSU Libraries indicates on its Ask-AQuestion Web site that questions will be answered within two working days, Monday through Friday. 


\begin{tabular}{|c|c|c|}
\hline \multicolumn{3}{|c|}{$\begin{array}{c}\text { TABLE } 1 \\
\text { Average Turn-Around Time by } \\
\text { Patron Group }\end{array}$} \\
\hline $\begin{array}{l}\text { Selected } \\
\text { Group }\end{array}$ & $\begin{array}{c}\text { \# of Questions } \\
\text { Received }\end{array}$ & $\begin{array}{c}\text { Average } \\
\text { TAT in Days }\end{array}$ \\
\hline Alumni & 42 & 3.318981757 \\
\hline Faculty & 67 & 1.956984349 \\
\hline Graduate & 152 & 1.606054307 \\
\hline Other & 138 & 1.744540476 \\
\hline Staff & 66 & 1.040554679 \\
\hline Undergraduate & 108 & 1.568559456 \\
\hline Total: & 586 & 1.796583818 \\
\hline
\end{tabular}

assigned questions, only those who received more than 10 questions during the study period were examined. The data indicate significant variability exists when a patron question is referred to an individual specialist or specialist group for answer. Specialist reference questions took an average of seven hours longer to answer than directional or basic reference questions. This delay may reflect the additional step of referring the question to another individual for response, a component of the service process that may require future thought and attention. It is important to note, however,

Questions were examined for the actual time it took to answer a question, regardless of whether Saturday and Sunday was included. When analyzed this way, 65 of the 586 questions asked during the study period were not answered within 48 hours, representing 11 percent of all questions. Excluding weekends, this delay can be explained in some instances by the exchange of follow-up questions that is sometimes required to answer a patron's question. The OSU University Archives, for example, is a closed, noncirculating collection. Patrons must work with an archivist to identify and arrange access to the material. Overall, however, the average turnaround time for a question asked through the Ask-A-Question Web site was 1 day, 19 hours (table 1). By patron category, alumni waited the longest, with average turnaround time of 3 days, 8 hours. This is difficult to explain, but it may reflect librarians' perception that faculty, student, and staff questions must receive priority. Faculty questions were answered within 1 day, 23 hours on average, while staff had the shortest wait time, with 1 day, 1 hour. Turnaround time for questions assigned to a specialist or specialist group is listed in table 2. Because of the number of specialists or specialist groups that the data for one assigned group may reflect a one-time special cause variation, as a transition of responsibilities occurred on February 1, 2008, with the retirement of a business librarian.

\section{Improve}

While the problem has been defined, measured, and analyzed, a significant amount of work remains to improve and control the process. The author gave a presentation on the project to a meeting of public service librarians and paraprofessional

\begin{tabular}{|c|c|c|}
\hline \multicolumn{3}{|c|}{$\begin{array}{c}\text { TABLE } 2 \\
\text { Average Turn-Around Time by Select } \\
\text { Assigned Group }\end{array}$} \\
\hline $\begin{array}{l}\text { Assigned } \\
\text { Group }\end{array}$ & $\begin{array}{l}\text { \# of Questions } \\
\text { Received }\end{array}$ & $\begin{array}{c}\text { Average TAT } \\
\text { in Days }\end{array}$ \\
\hline Administration & 26 & 2.108423255 \\
\hline Archives & 106 & 1.648987814 \\
\hline Business & 13 & 8.557061075 \\
\hline Central & 241 & 1.090017769 \\
\hline Circulation & 44 & 2.670010522 \\
\hline Education & 10 & 1.402359954 \\
\hline Health Sciences & 13 & 1.858674323 \\
\hline Maps & 19 & 2.356537524 \\
\hline $\begin{array}{l}\text { Electronic } \\
\text { Resources }\end{array}$ & 49 & 1.449047147 \\
\hline SEL & 24 & 2.7872989 \\
\hline Total: & 586 & 1.796583818 \\
\hline
\end{tabular}


library assistants in May 2008. The presentation included the SIPOC diagrams, Pareto charts, and the tables with the average turnaround time calculated by patron type and assigned group. Librarians answering questions in the Questionpoint system were gently reminded to include follow-up language and note whether a question was answered outside the Questionpoint system to help the project team better determine the root causes of the service denial issue. To address the fact that specialist reference questions took an average of seven hours longer to answer, the project team took steps to empower the paraprofessional to answer certain types of questions, as long as the subject specialist's phone number was included in the answer in case the patron required more in-depth information.

An initial review of answers to questions submitted in June and July of 2008 has indicated that these interventions have improved the quality and consistency of communications between library employees and patrons. An analysis of questions received and answered during Fall Quarter 2008 will need to be conducted, however, so that Sigma Level can be recalculated to verify the improvement. Theoretically, by addressing follow-up defects in questions and answers alone, the Libraries' Sigma Level should rise to 2.9.

Further, while the OSU Libraries does state that it will answer questions within two working days Monday through Friday, the data collected from this project suggest that it may be time for the OSU Libraries to revisit this policy. Over time, prompt response to a patron query moves from being a delighter to an expectation, just as cupholders and keyless entry in vehicles are now considered standard. ${ }^{14}$ Answers to questions related to Electronic Resources, for example, may also lose their relevance for the patron as time passes, especially when the patron has a time-sensitive information need. Additional exploration of the causes for answer delays using techniques such as value stream analysis is necessary, along with reconsideration of the library's policy to answer questions within two working days during regular working hours Monday through Friday.

\section{Control}

Once the process is improved, a plan to monitor and control the improved process must be established to sustain the change and ensure that the solution can continue to improve in the future. Steps to standardize the improved process, through the establishment of agreed-upon policies and procedures, need to be taken to ensure the process is performed both consistently and effectively. Following the author's presentation to public services librarians and paraprofessionals during the Improve phase, it was apparent that, while the RUSA Guidelines are an appropriate standard, there is a wide variety of interpretations of these guidelines by OSU librarians and paraprofessional library assistants. Since this issue was outside the scope of the current project, a second project team was established in July 2008 to draft a locally agreedupon standard for interpreting the RUSA Guidelines that could be incorporated into the policies and procedures for the OSU Libraries' e-mail reference service.

Sampling strategies to monitor the improved process must be identified next, so that data can be promptly collected and reported using Control charts, Frequency plots, Pareto charts, and other quality management tools. Control charts are particularly helpful for monitoring the sustained improvement of a process. If set up appropriately, they facilitate quickfeedback loops that help employees to determine whether a problem must be addressed immediately or can be attributed to a one-time special cause. Regardless of the tool selected, a strategy for continuous improvement of the process must be established, along with a mechanism for closing the project and transferring full responsibility for the operation and improvement of the process back to the process owner. 


\section{Discussion}

Lean Six Sigma is just one of many philosophies and process improvement methodologies libraries can leverage to facilitate change. The system does not need to be used exclusively of other quality improvement programs. It does, however, provide an infrastructure for supporting change and a discipline to examine and continually improve service processes. The example of using the DMAIC framework and associated quality management tools to improve the OSU Libraries' e-mail reference service, like any other research project, has limitations that must be disclosed. Only one librarian representative, for instance, participated on the project team. The author evaluated all answers to the 586 e-mail questions received for conformance to RUSA guidelines. While the RUSA guidelines may attempt to state clearly what constitutes behaviors for effective reference service, the variability among librarians' perceptions of what truly constitutes a complete, accurate answer, or even follow-up language, can be problematic. To verify the veracity of the operational definitions and their application in the analysis, the second project team charged to establish locally agreed-upon standards for interpreting the RUSA guidelines must conduct a Gage R\&R analysis. Gage R\&R is a statistical tool that measures the ability of a measurement instrument to produce the same results when studying one sample repeatedly and the ability of different operators to reproduce results when using the same sample and instrument. This means that, if the author reevaluated the answers to the 586 e-mail questions again, she would need to be able to repeat the same results in the Excel spreadsheet. Other peer librarians on the project team would need to be able to reproduce the same results using the same Excel spreadsheet.

While many companies have used Lean Six Sigma to improve their op- erations, the Lean Six Sigma approach to quality has its own limitations and cannot address all problems. A true companywide deployment of a Lean Six Sigma initiative requires top-down administrative support in selecting and providing both human and financial resources for projects to succeed. Further, the initiative must be well aligned with the organization's strategy. Processes must exist first for projects to be identified, which also leads to the assumption "that the existing process design is fundamentally sound and just needs minor adjustments to be more efficient." 15 The framework may discourage rethinking or introducing entirely new ways to execute a process.

There are also questions as to whether Lean Six Sigma could be sustainable in the library environment. Most libraries struggle to maximize patron service with significant budgetary constraints. Training staff in the various levels of Six Sigma knowledge requires a significant investment of both time and financial resources. ${ }^{16}$ Other continuous quality improvement programs, such as ISO 9001 or the Malcolm-Baldridge National Quality Award, have already been successfully implemented by other library organizations and may also prove to be useful for encouraging a library organization to establish an infrastructure that supports a culture of assessment and change. ${ }^{17}$

Libraries can customize and borrow a number of quality management systems and tools from the business community to both assess their service process and continuously improve their operations. By adopting an approach like Lean Six Sigma, a library can respond better to changing customer needs and desires by creating an infrastructure that supports, nurtures, and sustains a culture of assessment and change.

\section{Notes}

1. Examples include: Association of Research Libraries, Library Assessment Conference: Build- 
ing Effective, Sustainable, Effective Practice, Seattle, WA, August 4-6, 2008, available online at http:// libraryassessment.org [accessed 13 June 2008]; and Association of Research Libraries, Service Quality Evaluation Academy, available online at www.arl.org/stats/statsevents/sqacademy/index. shtml [accessed 13 June 2008].

2. For detail on the history and development of Lean, see James P. Womack, Daniel T. Jones, and Daniel Roos, The Machine that Changed the World: The Story of Lean Production-Toyota's Secret Weapon in the Global Car Wars That Is Revolutionizing World Industry (New York, N.Y.: Free Press, 2007). For detail on the history and development of Six Sigma, see Peter S. Pande, Robert P. Neuman, and Roland R. Cavanagh, The Six Sigma Way: How GE, Motorola, and Other Top Companies Are Honing Their Performance (New York, N.Y.: McGraw-Hill, 2000).

3. James A. Fitzsimmons and Mona J. Fitzsimmons, Service Management: Operations, Strategy, Information Technology, 6th ed. (Boston, Mass.: McGraw-Hill Irwin, 2008).

4. Kai Yang, Design for Six Sigma for Service (New York, N.Y.: McGraw-Hill, 2005), 6.

5. Arne Buthmann, "Cost of Quality: Not Only Failure Costs," iSixSigma Europe. Available online at http://europe.isixsigma.com/library/content/c070502a.asp. [Accessed 13 June 2008].

6. Daniel L. Gee, "A Six Sigma Primer for Health Care Providers," in Business of Medical Practice: Advanced Profit Maximization Techniques for Savoy Doctors, ed. David E. Marcinko (New York, N.Y.: Springer Pub., 2004), 127-42.

7. For more information in 5S, see "Lean Manufacturing," Wikipedia. Available online at http://en.wikipedia.org/wiki/Lean_manufacturing. [Accessed 22 August 2008].

8. Library articles on Six Sigma include: I.V. Malhan and Shivarama Rao, "Application of Six Sigma in Libraries Part 1," Managing Information 12, no. 7 (Sept. 2005): 46-48; I.V. Malhan and Shivarama Rao, "Application of Six Sigma in Libraries," Managing Information 12, no. 8 (Oct. 2005): 48-50; I.V. Malhan and Shivarama Rao, "Application of Six Sigma in Libraries Key Elements, Problem, Conclusions," Managing Information 12, no. 9 (Nov. 2005): 58-59; Vivien McBride, "Six Sigma = Self Service Success," SCONUL Focus no. 39 (Winter 2006): 29-31; Biswanath Dutta and K.K. Chowdhury, "Application of Six Sigma in the Indian Statistical Institute Library (Banglore): A Case Study," Information Studies 10, no. 3 (July 2004): 573-94; and Chitra Kaushik et al., "Six Sigma Application for Library Services," DESIDOC Bulletin of Information Technology 27, no. 5 (Sept. 2007): 35-39.

9. For examples, see Cynthia Karen Swank, "The Lean Service Machine," Harvard Business Review 81, no. 10 (Oct. 2003): 123-29; Sherree Geyer, "Car Maker's Production System Helps Cancer Center Get Lean," Health Facilities Management 18, no. 8 (Aug. 2005): 5-6; and Edward D. Craven et al., "NewYork-Presbyterian Hospital Uses Six Sigma to Build a Culture of Quality and Innovation," Journal of Organizational Excellence 25, no. 4 (Sept. 2006): 11-19.

10. Association of Research Libraries, ARL Statistics 2005-2006: A Compilation of Statistics from One Hundred and Twenty-Three Members of the Association of Research Libraries (Washington, D.C.: Association of Research Libraries). Available online at www.arl.org/bm doc/arlstats06.pdf. [Accessed 13 June 2008].

11. American Library Association, Reference and User Services Association, Guidelines for the Behavioral Performance of Reference and Information Service Providers (Chicago, Ill.: American Library Association). Available online at www.ala.org/ala/rusa/protocols/referenceguide/guidelinesbehavioral.cfm. [Accessed 13 June 2008].

12. iSixSigma, "Yield to Sigma Conversion Table." Available online at www.isixsigma.com/ library/content/sigma_table.asp. [Accessed 13 June 2008].

13. iSixSigma, "Pareto." Available online at www.isixsigma.com/dictionary/Pareto-60.htm. [Accessed 13 June 2008].

14. For additional information on Professor Noriaki Kano's theory of product development and customer satisfaction, see "Kano Model," Wikipedia. Available online at http://en.wikipedia. org/wiki/Kano_model. [Accessed 17 June 2008].

15. Michael Hammer, "Process Management and the Future of Six Sigma," MIT Sloan Management Review 43, no. 2 (2002): 26-32.

16. The American Society for Quality offers training and certification courses in the Lean Six Sigma Body of Knowledge. See American Society for Quality, Lean Six Sigma Black Belt for Service-Blended Format, available online at www.asq.org/courses/blended-lean-six-sigma-blackbelt-service.html [accessed 16 June 2008]; and American Society for Quality, Lean Six Sigma Green Belt-Service Version, available online at www.asq.org/quality-press/self-paced-learning/index. pl?item=LSSGBS01MS [accessed 16 June 2008].

17. Despina Dapias Wilson, Theresa Del Tufo, and Anne E. C. Norman, The Measure of Library Excellence: Linking the Malcolm Baldrige Criteria and Balanced Scorecard Methods to Assess Service Quality (Jefferson, N.C.: McFarland, 2008); "ISO Quality as a Driver of Continuous Improvement," Performance Measurement \& Metrics 8, no. 2 (July 2007): 88-97. 


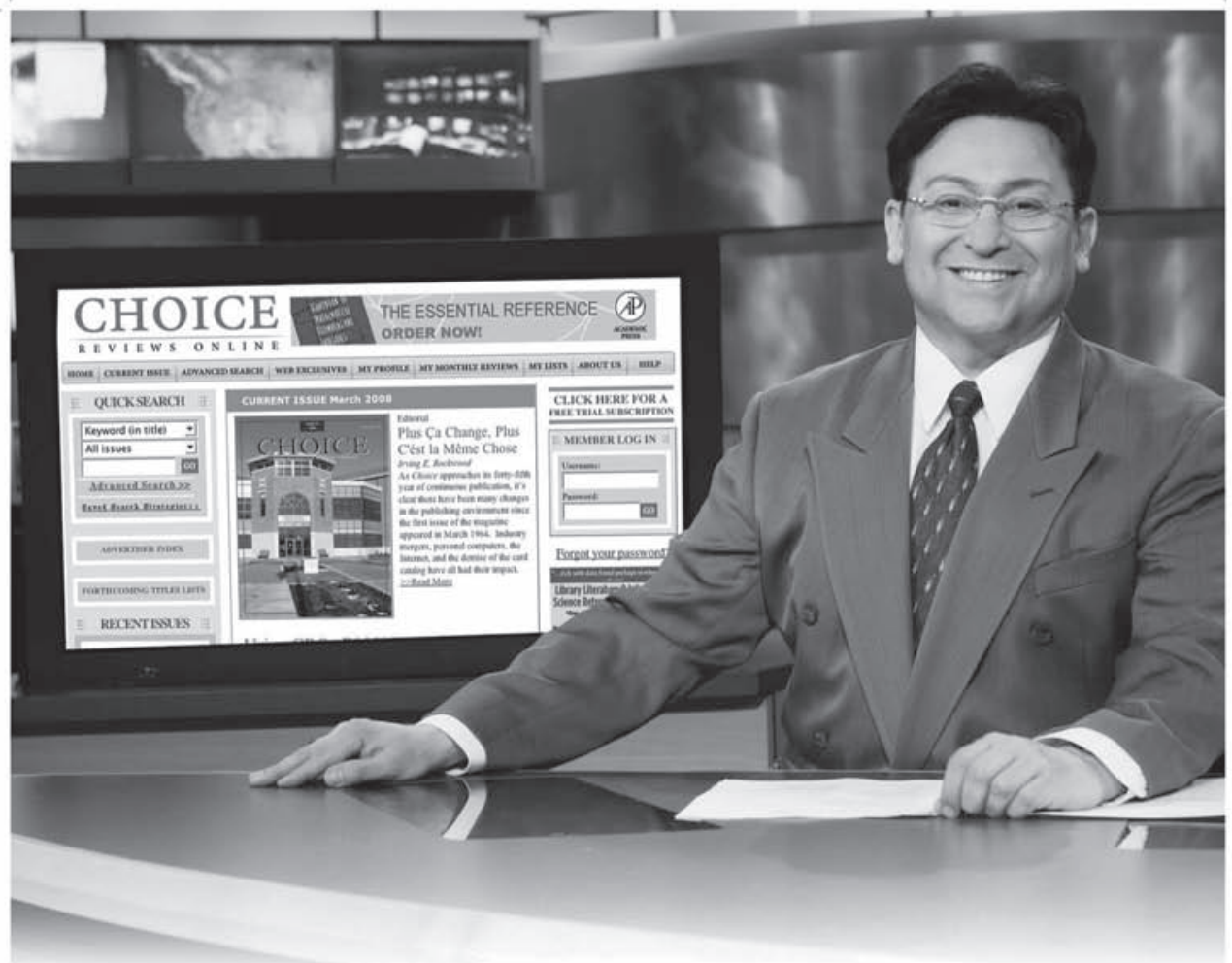

\section{See What People Are Saying About CHOICE REVIEWS ONLINE...}

"The advanced search on Choice Reviews Online is amazing!"

"I rely very heavily on Choice Reviews Online for my own library and book orders - they are the best resource out there."

"Choice Reviews Online is great! It really helps me make decisions about what to buy or recommend."
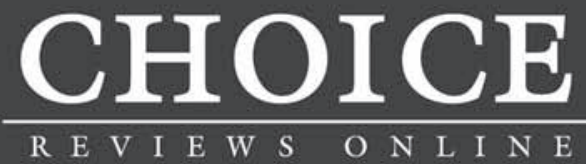

- The Perfect Companion to the CHOICE Print Subscription

- Access to Over 125,000

CHOICE Reviews

- Download, Print, or E-mail Search Results

- Ability to Create a Customized Profile

- Create, Save, and E-mail Lists

- Search All CHOICE Content

- View Exclusive Online Material

To learn more about

Choice Reviews Online, visit us at www.cro2info.org or sign up for a free 60-day trial at www.cro2.org 